\title{
Design and Development of Agriculture Sprayer Vehicle
}

\author{
Siddharth Kshirsagar*, Vaibhav Dadmal, Prashant Umak, Govind Munde and P. R. Mahale \\ †Department of Mechanical Engg, MIT College of Engg, Savitribai Phule University, Pune, India \\ Accepted 02 March 2016, Available online 15 March 2016, Special Issue-4 (March 2016)
}

\begin{abstract}
The population of the world is increasing rapidly. In order to fulfill their diet needs the production of food must be increased, but this must come at a cost affordable to everyone. Mechanization of agriculture enables conservation of inputs by precision in ensuring better distribution, reducing quantity required for better response or prevention of losses or waste of inputs applied. Mechanization reduces unit costs of production through higher productivity levels and the input conservation. The all agriculture equipment's often are hardly modernized due to its low productivity. In India farming is done by traditional ways, besides that there has been large development of industrial and service sector as compared to that of agriculture sector. The spraying of pesticides and insecticides is traditionally done by farm worker carrying backpack type sprayer which requires more human effort. Giving attention to these important problems an attempt is made to develop an equipment which will be beneficial to the farmer for the spraying operations. This equipment is easy to use and operate. It makes use reciprocating pump that creates the required pressure for the spraying action. This multifunction device will come in handy that can be put to use in different spraying stages of farming as per process requirement.
\end{abstract}

Keywords: Mechanization, input conservation, reciprocating pump.

\section{Introduction}

\section{A. Status of Agriculture in India}

India is predominantly an agricultural based country with approximately $75 \%$ of population of India is very much dependent on farming either directly or indirectly. The farmers have been using the same methods and equipment for ages for example the seed sowing, spraying, weeding etc. operations are carried out by same techniques. There is need for development of an effective spraying machine for increasing productivity levels. Most of the late developing countries of Asia have the problem of higher population and low levels of land productivity as of compared to the developed nations. One the main reasons for lower productivity is insufficient power availability for the farms and very low levels of farm mechanization. This is especially true for India.

\section{B. Mechanisation of Agriculture}

It is now accepted all over the world that in order to meet the food requirements of growing populations and rapid industrialization, the modernization of agriculture is indispensable. It is said that at many farms, production suffers due to no use of farm fertilizers or correct time pesticides and insecticides or improper application of these at required destination area of the affected crop. Mechanization enables conservation of inputs by precision in metering and ensuring better distribution, reducing the level of quantity required for the best response and prevention of loss or wastage of inputs applied. The Mechanization reduces the unit costs for the production by the high level of productivity and by input conservation.

Agricultural equipment's and machinery program of the governments has been one of selective mechanization with a view of optimising the use of human, animal and other source of power. In order to meet requirements, steps are taken to increase availability of implement, irrigation pumps, tractors, power tiller, combine harvesters and other power operated machines and also for to increase the production and availability of improved animal driven implements. Special emphasis was given on the later as more than the $70 \%$ of the farmers fall in small and marginal categories.

It is usually said that mechanization of small farms is difficult. But in Japan having average land holding even smaller of than ours, with proper mechanization has led agriculture to greater heights. In order to minimize the drudgery of the small farmers, to increase efficiency and save the farmer time which is taken for the taking up of additional supplementary and generating activities, also for use of modern time saving machines or implements of appropriate size needed to be suitably promoted therein. 
The nature of agriculture, does not admit of so many subdivisions of the farm labor, nor of so complete a separation of the one business from another, as in manufactures. It is impossible to separate so entirely the business of a grazer from that of the corn-farmer as the trade of the carpenter is commonly separated from that of smith. Spinner is almost always distinct person from the weavers; but the ploughman, the harrower, the sower of the seed, the reaper of the corn, are often same. The occasion for those different sorts of labor returning with the different season of the year, it is impossible that one man must be constantly employed in any one of these. This impossibility of doing so complete and an entire a separation of all the different branches of labors employed in the agriculture is the reason why the improvement of productive powers of labors in this fields does not always keep pace with their improvements in manufactures.

\section{Literature Review}

\section{A. Existing Spraying Methods:}

I. Hand operated sprayers (backpack with spray pump)

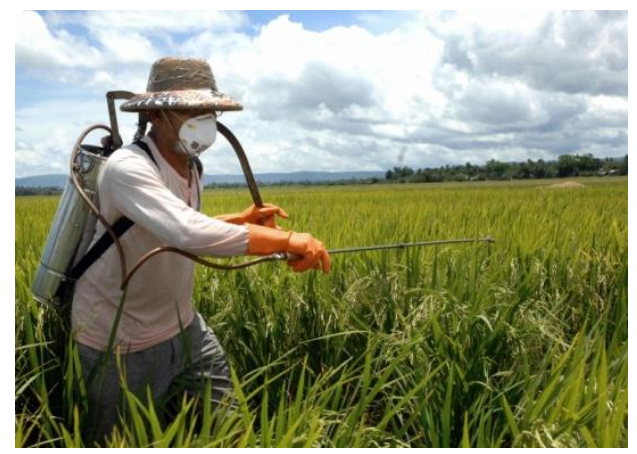

Fig.1 Hand operated sprayers.

Backpack sprayer are fitted with a harness so the sprayers can be carried on the operator back. Tank capacity may be large as 20 liters. A hand lever is continuously operated for to maintain the pressure which make the backpack sprayers output more uniform than that of a handheld sprayers. Basic low cost backpack sprayer will generate only low pressure and lack feature such as high-pressure pumps, pressure adjustment control (regulator) and pressure gauge found on commercial grade units.

\section{Engine driven sprayers.}

The engine operated sprayers typically produce more consistent sprayer's outputs, cover the sprays swath more uniformly, operate at constant speed and results in much more uniform coverage than the hand spraying. Motorized sprayer are also capable of higher pressure spray where required to provide a better coverage. There are many other type of hand operated sprayer that are not widely used throughout the agriculture. Some may be used wide extensively for the productions of specific commodities.

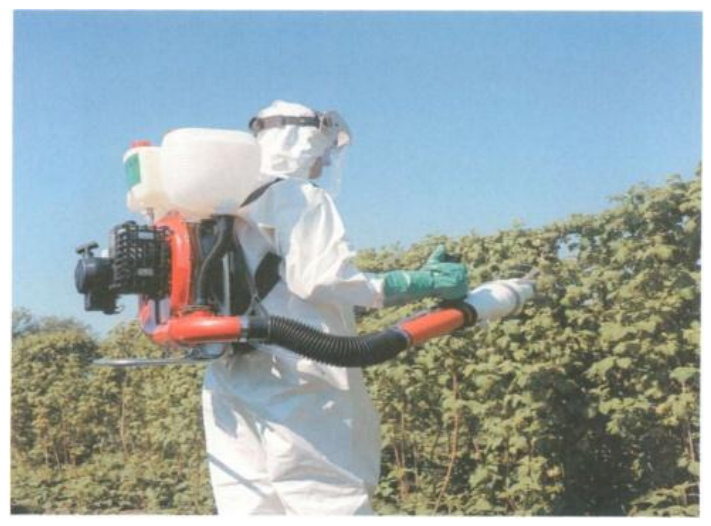

Fig.2 Engine driven sprayers.

III. High pressure sprayer.

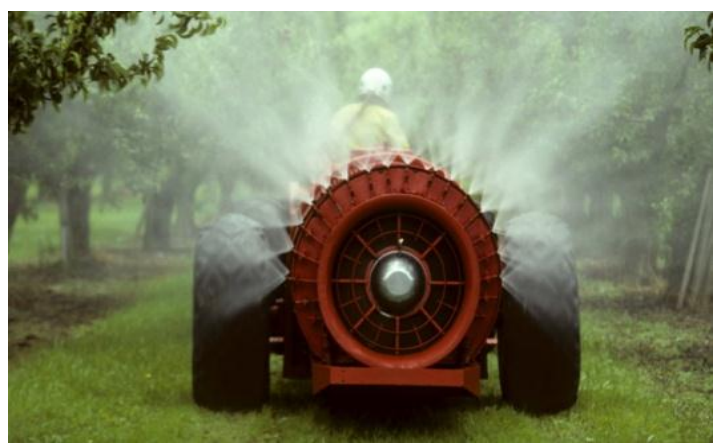

Fig.3 High pressure sprayer

The High pressure sprayer are often called as hydraulic sprayers. They usually operate with a dilute mixture and at different pressure from two hundred and fifty up to several hundred psi limits. The design of high pressure sprayer is similar to that of low pressure sprayer, the only difference is that the component have to withstand high pressure.

When fitted with boom they can do any work done by the suitable low pressure boom sprayers. These can also be fitted with handgun. The handgun are used for spraying shade tree and ornamental, livestock, orchards, building, unwanted brush, rights-of-way, commercial crop etc.

\section{B. Conclusion from Existing Spraying Methods.}

I. Mechanisation for spraying operation is costlier for specialised operations such as High pressure sprayer, Engine operated sprayer.

II. Skills of labour required depends upon the complexity of the equipment machinery used.

III. All the pre-existing methods have concentrated on providing feasible easy solutions to reduce cost of 
production by reducing cost of mechanisation and increasing productivity.

\section{Design Methodology}

\section{A. Problem Statement}

Agricultural sprayer vehicle should be able to work with help of appropriate controls in order to spray effectively along the path as required to perform the required functions. Based on these factor, the basic mechanical designs of agricultural sprayers vehicle will be designed and implemented for 3 liters of payloads by combining all the factor such as stated above with goal of achieving a better functionality.

\section{B. Objectives}

I. Decrease the operational costs by using new mechanisms.

II. Work reliably as under different working condition.

III. Decrease the costs of machine.

IV. Decrease labour costs by advancing the spraying methods.

V. Machine should be operated in small farming land with the standard spacing.

\section{Methods and Materials}

I. System designs as to and theoretical derivation of dimension of the kinematic linkage mechanisms.

II. Selection of pumps and drive for spraying applications.

III. Selection \& designs of pinion and gear drive system for the wheel shafts to pump driver linkage mechanisms.

IV. Design validation of the stress produced in the parts like input shafts, crank, connecting links, output links.

\section{Mechanical Subsystem}

\section{A. Base frame or chassis}

The base of frame of chassis is a mild steel fabricated structures that holds the entire assembly of the sprayers. The rear sides carries the rear wheel shaft that carries the rear wheel, the front wheels steering carries the front wheels bracket which provides the necessary turning effects.

\section{B. Drive Assembly}

The drive assembly consist of the driver pinion on rear shafts, and the spur gear on the crank. Thus when the vehicle move in forward directions the wheel will rotate the rear wheels shaft and hence the driver gear drive the driven gear and there by the intermediate shafts and the pitman arms which reciprocates the piston of sprayer.

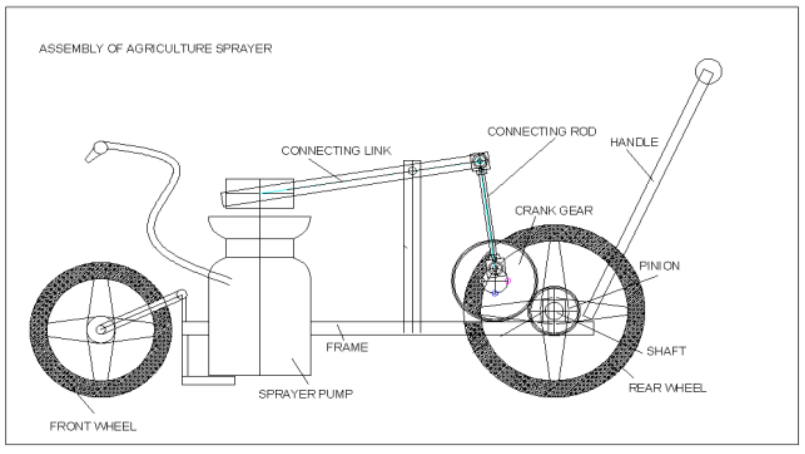

Fig.4 Side view of the model

\section{Pump System}

The pump systems comprises of sprayer mechanisms of 3 litre capacity integrated with an inbuilt pump and sprayer.

\section{Air storage and pesticide storage}

Compressed air is stored in the air chamber of storage tanks and the pesticides is stored in the liquid chamber, the sprayers connected to the tanks sprays this liquid pesticides using the compressed air.

\section{Design Parameters}

Table 1 Experimental procedure parameters

\begin{tabular}{|c|c|c|c|}
\hline S. No & Part & Material & Parameters \\
\hline 1 & Shaft & Alloy steel & Diameter $\mathrm{d}=12 \mathrm{~mm}$ \\
\hline 2 & Gear & Nylon 66 & Module $\mathrm{m}=1.25 \mathrm{~mm}$ \\
& & & Dp $=75 \mathrm{~mm}$ \\
& & & Dg $=150 \mathrm{~mm}$ \\
& & & BHN $=210$ \\
\hline
\end{tabular}

\section{Specifications}

\begin{tabular}{|c|c|c|}
\hline $\begin{array}{c}\text { Sr. } \\
\text { No }\end{array}$ & Title & Value \\
\hline 1 & Wheel diameter & $360 \mathrm{~mm}$ \\
\hline 2 & $\begin{array}{c}\text { Pump stroke per rotation of } \\
\text { wheel }\end{array}$ & 1 \\
\hline 3 & $\begin{array}{c}\text { Pump in ideal condition, rate } \\
\text { of discharge }\end{array}$ & $\begin{array}{c}250 \mathrm{ml} / \\
\text { minute }\end{array}$ \\
\hline 4 & $\begin{array}{c}\text { Delivery of pesticide liquid per } \\
\text { stroke of pump }\end{array}$ & $12.5 \mathrm{ml}$ \\
\hline
\end{tabular}

\section{Conclusions}

- The motive behind developing this equipment is to create mechanizations which will help to minimize effort of farming.

- It is suitable for the spraying at minimum costs for the farmers so that he can afford it, of the many product available. 
- It is most important to select the most efficient and easy type for your particular needs, whether if it is for applying insecticide fungicides, weed killer, liquid fertilizers or wettings agents. For example, lawn sprayers is made especially for the applications of liquids material to the lawn area.

- $\quad$ The sprayer is are metered to allow quick mixing and the coarse sprays, so it does not takes as long to apply weeds killers, insecticides etc. Also, there is also not as much chances of drifting of the liquids into nearby flowers and shrub bed. The old saying You get for what you pay for does apply to the sprayer.

- Efficiency and accuracy vary very much considerably, especially with the types that attaches to garden hose. Sprayer that are used for weeds killing or for applying any types of soil sterility should not be utilized for any other purposes. In fact, you will find it a very good practices to set sprayer to side just for the lawn areas. Use separate one for flowers and shrubs. It's a good practice to clean out your sprayers immediately after you used it for any type of the spraying. A little soapy water form, swished around and through sprayers, then flushed out with warm the water, does a good job.

So considering the above points related to spraying the project work is focused upon to design and to fabricate such equipment which will be able to perform spraying operation more efficiently and also will result in low cost.

\section{References}

R. Joshua, V. Vasu and P. Vincent (2010) Solar Sprayer - An Agriculture Implement, International Journal of Sustainable Agriculture 2 (1): 16-19, 2010 ISSN 2079-2107

R. D. Fox, R. C. Derksen, Visual and image system Measurement of spray deposits using water-sensitive Paper Applied Engineering in Agriculture Vol. 19(5): 5495522003 American Society of Agricultural Engineers ISSN 0883-8542

M. A. Miller, B. L. Steward, M. L. Westphalen Effects of multimode four-wheel steering on sprayer Machine performance, American Society of Agricultural Engineers ISSN 0001-2351

A. Taiwo K. Oje, Development and testing of a swirl Chamber nozzle, Journal of Agricultural Engineering And Technology (JAET), Volume 16 (N0. 1) June, 2008 A reference paper on plant protection Equipment published at journal of Agricultures. A reference paper on Spray Equipment and Calibration AE-73 (Revised)

Vern Hofman and Elton Solseng Agricultural and Biosystems Engineering North Dakota State University Fargo, North. A reference paper on Recent Developments in Sprayers for Application of Bio-pesticides - an overview by Samuel Gan Mor, Graham A. Matthews.

A reference paper on Pump Types for Water Supply or Spraying by Larry E. Stewart And Albert V. Krewatch.

R.Joshua, V.Vasua and P.Vincent, Solar Sprayer- an Agriculture Implement, published in International Journal of Sustainable Agriculture 2(1): 16-19, 2010 ISSN 20792107. 